Ashraf S Qassim BDS, MSc (Lec.)

Sabah A Ismail BDS, MSc (Asst.Prof)

Emad F Alkhalidi BDS, MSc (Lec.)

\section{The Effect of Sodium Hypochlorite on Shear Bond between Composite and Porcelain Specimens}

Dept of conservative Dentistry College of Dentistry, University of Mosul

Dept of conservative Dentistry College of Dentistry, University of Mosul

Dept of conservative Dentistry College of Dentistry, University of Mosul

$$
\begin{aligned}
& \text { الحلاصة } \\
& \text { الأهداف: الهدف من هذة الدراسة هو قياس الربط القصي بين مادة الحزف ومادة الراتنج الكمبوزيت المستعملة في ترميم التيجان والجسور الخزفية بأستخدام }
\end{aligned}
$$

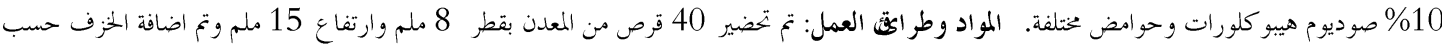

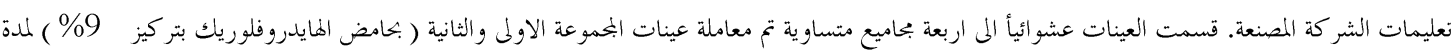

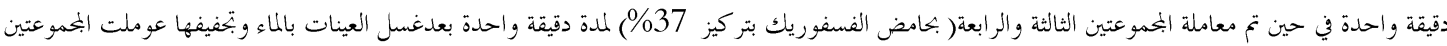

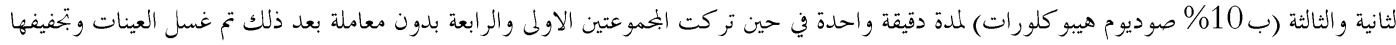

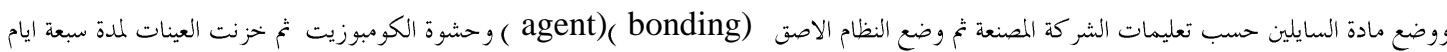

$$
\begin{aligned}
& \text { بعد ذلك تم تعريض العينات للاجهاد الحراري وبعدها تم قياس قوة الربط القصي باستخدام ( Universal tasting machine). النتائج: تم تحليل النتائج }
\end{aligned}
$$

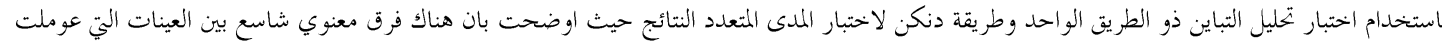

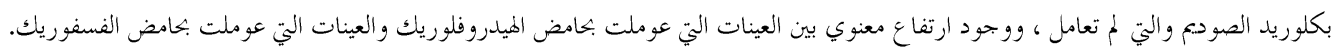

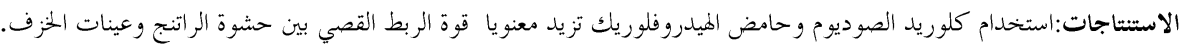

\begin{abstract}
Aim of Study: This in vitro study was conducted to evaluate the shear bond strength of intra oral porcelain repair system using 10\% sodium hypochlorite and different acid etch. Materials and methods: Forty specimens were prepared in form of metal disks $(8 \mathrm{~mm}$ in diameter, $15 \mathrm{~mm}$ height) and porcelain was applied according to the manufacturer instructions. The specimens randomly divided into 4 equal groups. In Group I ,II the samples were treated with $9 \%$ hydrofluoric acid for one minute. While groups III, IV were treated with $37 \%$ phosphoric acid for one minute, after washing the specimens with water and dryness, groups II, III the surfaces treated with $10 \%$ sodium hypochlorite for one minute while group I and IV leaved untreated. After that, the surfaces of all samples were washed and dried and silane coupling agent (MonoBond-S Vivadent, Liechtenstein) was applied according to the manufacturer instructions, then bonding agent (Excite) (Vivadent, Liechtenstein) and composite (tetric Nceram) (Vivadent, Liechtenstein) were applied according to the manufacturer instructions. All the samples were stored in normal physiological saline for 7 days. Then the samples were thermocycled manually between two water baths. After that Shear bond strength was tested using universal testing machine. Results: using ANOVA and Duncan's multiple range tests. The result showed that there was highly significant difference between groups treated with $10 \%$ sodium hypochlorite with untreated one. There was significant difference between samples acid etched using hydrofluoric acid with those etched with phosphoric acid. Conclusions: Sodium hypochlorite and hydrofluoric acid significantly increase the shear bond strength between composite resin and porcelain fused to metal specimens. Keywords: Hydrofluoric acid, phosphoric acid, sodium hypochlorite.
\end{abstract}

Qassim AS, Ismail SA, Alkhalidi EF. The Effect of Sodium Hypochlorite on Shear Bond between Composite and Porcelain Specimens. Al-Rafidain Dent J. 2012; 12(2): 316-320.

Received: 28/3/2011 Sent to Referees: $30 / 3 / 2011$

Accepted for Publication: 1/6/2011

\section{INTRODUCTION}

Ceramic based restorations are an important part of dentist s armamentarium for durability and esthetic, these materials with excellent biocompatibility are widely used to achieve highly esthetic characteristic in metal ceramic restoration. ${ }^{(1)}$

Porcelain fused to metal restoration 
has been one of the most common restorations used in fixed prosthodontics because of their casting accuracy, high strength properties of the metal, and the cosmetic appearance of porcelain. ${ }^{(2)}$

Porcelain fracture is a serious and costly problem for each the patient and the dentist. The problem is more critical if the fracture crown is part of a multiunit restoration. Remaking the crown or fixed partial denture is often in advisable and intra oral repair may be indicated. ${ }^{(3)}$

When attempting to repair a fractured ceramo metal restoration it is important to determine the reason for failure. If the failure is due to occlusion or substructure flexure, the repair will probably fail no better than the original restoration. However if the fracture is due to trauma or technical error during the construction of the original restoration, porcelain repair procedure may be the treatment of choice. $^{(4)}$

New porcelain repair systems showed excellent adhesion, durability of resin based to the fractured ceramic the clinical success of a repaired ceramic restoration will depend on the quality and durability of the bond between the ceramic and the resin composite. The new generations of adhesive systems are multipurposes systems capable of bonding composite to var-

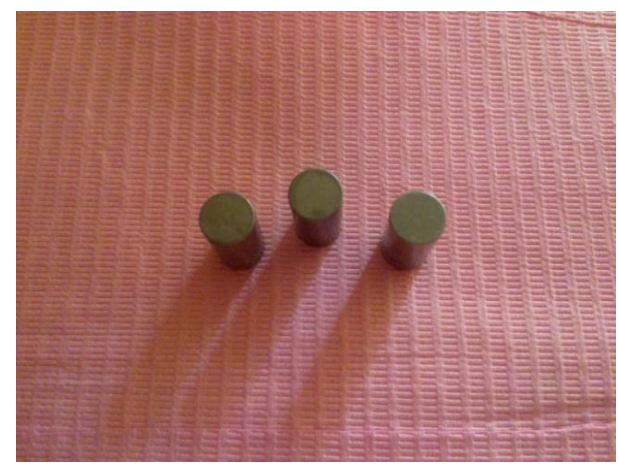

Figure (1): show the metal disk

Specimens randomly divided into 4 equal groups 10 samples for each.

Group I, II the samples were treated with $9 \%$ hydrofluoric acid for one minute. ious substrates (enamel, dentin, metal and porcelain). ${ }^{(5,6)}$ Many porcelain repair systems have been reported, each of them using silane coupling agents. ${ }^{(7)}$

Sodium hypochlorite is a non specific proteolytic agent that effectively removes organic compounds and has been frequently applied for collagen removal after acid etching with various and controversial results. ${ }^{(8,9)}$

The aim of this in vitro study is to evaluate the shear bond strength of intra oral porcelain repair system using $10 \%$ sodium hypochlorite and different types of acid etch materials.

\section{MATERIALS AND METHODS}

Forty specimens were prepared in form of metal disks $(8 \mathrm{~mm}$ in diameter, $15 \mathrm{~mm}$ height). Figure (1).

A thin wash layer of the opaque was applied according to the manufacturer's instructions. The specimen was dried and fired under vacuum to a specific temperature $(940 \mathrm{oC})$. A second creamy layer of the opaque was applied to the sample till it became dry and then was fired at $930 \mathrm{oC}$ after that Two layers of body porcelain were applied to the sample, the first one is a build up layer to build the mass of ceramic while the second one is added for correction, and firing at $920 \mathrm{oC}$. Figure (2)

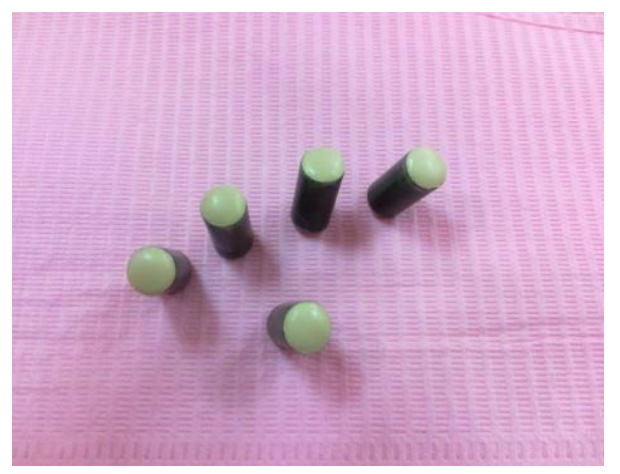

Figure (2) show the specimens after porcelain application

While groups III, IV were treated with $37 \%$ phosphoric acid for one minute

After washing with water, groups II, III the surfaces treated with $10 \%$ sodium 
hypochlorite for one minute while group I and IV leaved untreated.

Then all samples washed with copious amount of water for 15 seconds, and dried with oil-free air spray for 10 seconds. ${ }^{(10,11)}$

After that Silane coupling agent (MonoBond-S Vivadent, Liechtenstein) was applied following the manufacturer's directions in all groups and allowed to set for 60 seconds and dried for 10 seconds with oil-free air spray. ${ }^{(10)}$ Then Excite bonding agent (Vivadent, Liechtenstein) was applied according to the manufacturer's instructions.

Composite application: Using plastic transparent tube of $6 \mathrm{~mm}$ diameter and $2 \mathrm{~mm}$ high the composite (tetric $\mathrm{N}$-ceram) (Vivadent, Liechtenstein) were applied on the surface cover it with celluloid strip and light cured for 40 seconds (the tip of the nozzle was in intimate contact with the specimen).

Aging and thermocycling: All the samples were stored in normal physiological saline for 7 days. ${ }^{(6)}$

Then the samples were thermo cycled for 200 cycles. $^{(4)}$ Thermo cycling was done manually between two water baths the temperature of one bath was maintained at $5^{\circ} \mathrm{C} \pm 2{ }^{\circ} \mathrm{C}$ and the other bath at $55^{\circ} \mathrm{C} \pm 2^{\circ} \mathrm{C}$. The immersion time was for 30 seconds in each bath. ${ }^{(12,13)}$
Testing procedure: Shear bond strength were tested with universal testing machine using chisel shaped rod, which is specially designed to deliver the shearing force, the chisel end of the rod was positioned at the interface between the sample surface and composite .

The specimens were secured tightly in place to ensure that the cylinder was always at $90^{\circ}$ to the vertical plane.

The specimens were loaded until they failed; the forces were recorded in Newton which has been divided by the surface area to obtain shear bond strength calculated in Mpa.

\section{RESULTS}

The descriptive analysis of the four groups in table 1 showed that group II gave rise to the highest mean while group IV gave rise to the lowest one.

In table 2 the statistical analysis of data by using the analysis of variance "ANOVA" revealed that there was highly significant difference among the different groups where $\mathrm{p} \leq 0.001$.

Duncan's multiple range test in table 3 showed that group II showed significant increase as compared with other groups while group IV showed significant decrease in comparism with remaining groups, finally group I and group III significantly distributed between the former and the later groups.

Table (1): Descriptive analysis involve

\begin{tabular}{ccccccc}
\hline groups & N & Minimum & Maximum & \multicolumn{1}{c}{ Mean* } & SD & SE \\
\hline 1 & 10 & 11.30 & 12.86 & 12.17 & .54 & .17 \\
2 & 10 & 13.80 & 15.60 & 14.94 & .52 & .16 \\
3 & 10 & 10.98 & 12.08 & 11.48 & .35 & .11 \\
4 & 10 & 7.95 & 10.02 & 9.10 & .59 & .19 \\
\hline
\end{tabular}

*mean measurement in mega Pascal.

Table (2): ANOVA test between groups

\begin{tabular}{cccccc}
\hline & Sum of Squares & Df & Mean Square & F & p-valu \\
\hline Between Groups & 173.221 & 3 & 57.740 & 222.662 & 0.000 \\
Within Groups & 9.335 & 36 & .259 & & \\
Total & 182.557 & 39 & & & \\
\hline dff:degree of freedom & & & &
\end{tabular}

d.f:degree of freedom 
Table (3): DUNCAN

\begin{tabular}{cccc}
\hline Groups & $\mathrm{N}$ & Mean \pm SD & Duncan Groups* \\
\hline 4 & 10 & $9.10 \pm .59$ & $\mathrm{~A}$ \\
3 & 10 & $11.48 \pm .35$ & $\mathrm{~B}$ \\
1 & 10 & $12.17 \pm .54$ & $\mathrm{C}$ \\
2 & 10 & $14.94 \pm .52$ & $\mathrm{D}$ \\
\hline
\end{tabular}

1: group I (samples treated with hydrofluoric acid ).

2: group II (samples treated with hydrofluoric acid +sodium hypochlorite).

3: group III (samples treated with phosphoric acid +sodium hypochlorite).

4: groupIV (samples treated with hydrofluoric acid).

\section{DISCUSSION}

Bond strength tests have been used to predict the clinical performance of repaired fractured ceramic restorations and resin-bonded ceramic restorations, even though most of these tests exhibit a wide variability in fracture patterns and bond strength. ${ }^{(14,15)}$

Factors influencing resin bonding to ceramic include the wettability of ceramic by adhesive resins, the roughness of ceramic surface, the composition of adhesive resins, the handling performance of adhesive resins, and possible contamination during bonding procedures. ${ }^{(11,13)}$

The clinical success of a repaired ceramic restoration will depend on the quality and durability of the bond between the ceramic and the resin composite. The quality of this bond will depend upon the bonding mechanisms that are controlled in part by specific treatment to promote micromechanical andlor chemical retention with the substrate. ${ }^{(14)}$

Acid-etching was the single most effective procedure for enhancing and retaining bond integrity, Etching procedures are used to facilitate bonding between the ceramic surface and the composite resin because it creates a porous in the ceramic surface this porosity lead to increase the retentive bond between the resin and ceramic. $^{(5)}$

Effective etching of the ceramic surface is considered an essential step for the clinical success of repaired ceramic prostheses. Structural and surface analyses of etched ceramics have showed that different etching patterns are created according to the ceramic microstructure and composition and the concentration, application time, and type of etchant. ${ }^{(15)}$

In this study the hydrofluoric acid produces high shear bond strength than groups treated with phosphoric acid, this agrees with the result of Della Bona ${ }^{(10)}$ who reported that hydrofluoric acid etching produce aggressive effect on the surface of ceramic.

Hydrofluoric acid suggest an associated preferential dissolution of one of the phases of porcelain. ${ }^{(10)}$

This result agree with the result of $\mathrm{Ku}$ piec et al ${ }^{(5)}$ who concluded that porcelain treatment with aluminum oxide air abrasion followed by hydrofluoric acid in conjunction with bonding regimens with a silane coupling agent generated the greatest bond strengths of composite to porcelain.

Sodium hypochlorite has wide range of using in dentistry it has bleaching ability, cleaning and disinfection effect and has ability to dissolve the organic material ${ }^{(8)}$, in this study the sodium hypochlorite showed direct effect in enhancement the bond strength between the composite and ceramic this could be related to the fact that sodium hypochlorite is strong cleaning, so increase the wetting of the surface of porcelain and this will increase the bond strength between the porcelain and adhesive resin.

\section{CONCLUSIONS}

Sodium hypochlorite and hydrofluoric acid significantly increase the shear bond strength between composite resin and porcelain fused to metal specimens.

\section{REFERENCES}

1. Lacy AM, Laluz J, Watanabe LG, Dellinges M. Effect of Porcelain Surface Treatment on Bond to Composite. J Prosthet Dent. 1988; 60:288-291.

2. Aschheim KW, Dale BG. Esthetic dentistry. A clinical approach to tech- 
nique and materials. 2nd ed., Mosby Co. 2001; ch: 3,4 and 7.

3. Kappert HF. Modern metal ceramic system. Dent News. 1998; 11: 29-40.

4. Haselton D.R, Diaz-Arnold Am, Dunne JT. Shear Bond Strength of 2 Intra oral Porcelin Repair Systems to porcelian or metal substrates. J prosthet Dent. 2001; 86:526-531.

5. Kupiec KA, Wuertz KM, Barkameier WW. Evaluation of porcelain surface treatment and agents for composite to porcelain repair. J Prosthet Dent. 1996; 76: 119-124.

6. Aida M, Hayakawa T, Mizukawa K. Adhesion of composite to porcelain with various surface conditions. J Prosthet Dent. 1995; 73: 464-470.

7. Chen JH., Matsumura H., Atsuta M. Effect of etchant, Etching period, and Silane priming on Bond Strength of composite to porcelain. Oper. Dent. 1998; 23:250-257.

8. Sakae T, Mishima H, Kozawa Y: Changes in bovine dentin mineral with Sodium Hypochlorite treatment. J Dent Res. 1988; 67(9):1229-1234.

9. Saboia VPA, Pimenta LAF, Ambrosano GMB. Effect of collagen removal on microleakage of resin composite restorations. Oper Dent. 2002; 27:38-43.
10.Bona A.D. characterizing ceramics and the interfacial adhesion to resin:the relation ship of surface treatment, bond strength interfacial toughness and fractography. J appl oral sci. 2005; 13:101109.

11.Galindo DF, Ercoli C, Graser GN, Tallents RH, Moss ME. Effect of soldering on metal-porcelain bond strength in repaired porcelain fused to metal castings. J Prosthet Dent. 2001; 85: 88-94.

12.Staninec M, Mochizuki A, Tanizaki K, Fukada K, Tsuchitani Y. Interfacial space, marginal leakage, and enamel cracks around composite resins. Oper Dent. 1985; 11: 14-24.

13. Kussano CM, Bonfant G, Batista JG and Pinto JHN. Evaluation of shear bond strength of composite to porcelain according to surface treatment. Braz Dent J. 2003; 14:132-135.

14.Bona AD, Anusavice KJ, Shen C. Microtensile Strength of composite bonded to hot pressed ceramics. J adhesive dent. 2000; 2: 305-313.

15.Bona AD, Anusavice KJ, MecholskyJJ. Apparent Interfacial Fracture Toughness of resinlceramic system. J Dent Res. 2006; 1037-1041. 